\title{
The effect of bilingualism on cognitive and auditory abilities in normally hearing adults
}

\author{
Geise Corrêa Ferreira ${ }^{(1)}$ \\ Enma Mariángel Ortiz Torres ${ }^{(1)}$ \\ Michele Vargas Garcia(1) \\ Silvio José Lemos Vasconcellos ${ }^{(1)}$ \\ Natalia Schopf Frizzo(1,2) \\ Maristela Julio Costa ${ }^{(1)}$
}

(1) Universidade Federal de Santa Maria, Santa Maria, RS, Brasil.

(2) Hospital Universitário de Santa Maria, Santa Maria, RS, Brasil.

Research carried out at the Universidade Federal de Santa Maria (UFSM), Santa Maria, RS, Brasil.

Research support source: scholarship granted by the Coordenação de aperfeiçoamento de pessoal de nível superior (CAPES)

Conflict of interest: Nonexistent

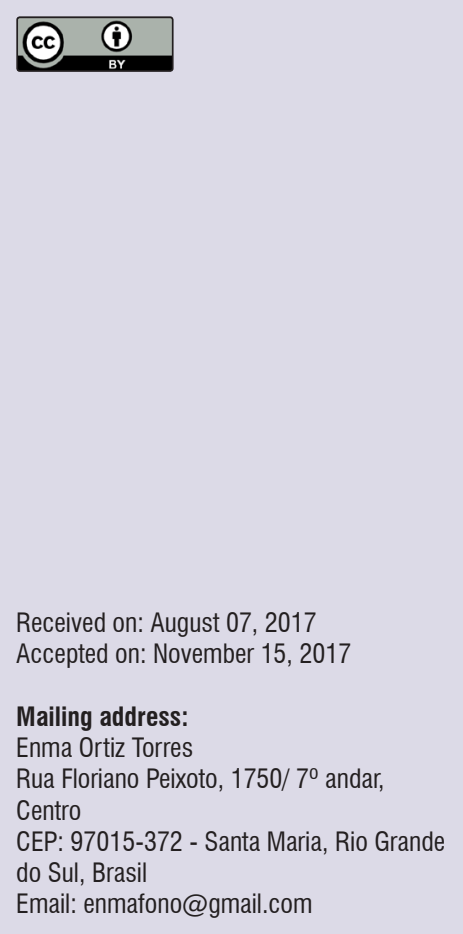

\section{ABSTRACT}

Purpose: to evaluate and compare cognitive and auditory abilities in normally hearing monolingual and bilingual individuals.

Methods: the sample consisted of 21 normally hearing individuals ranging in age between 18 and 25 years, divided into a control group of eight monolingual speakers of Brazilian Portuguese and a study group composed of 13 bilingual speakers of Brazilian Portuguese and German or Italian. The individuals underwent basic audiological assessments as well as assessments of cognitive and auditory figure-background abilities with the BPR-5 and SSW tests, respectively.

Results: the assessment of cognitive abilities showed that bilinguals had a better performance for the general cognitive function, with a statistically significant difference, as well as for cognitive abilities of verbal, spatial and mechanical reasoning. Also, for auditory figure-background abilities, there was a statistically significant difference between the study groups, with bilinguals showing a better performance.

Conclusions: based on the study groups, it was found that the bilingual subjects had a better performance of their general cognitive function, as compared with monolingual speakers, as well as in their specific cognitive abilities of verbal, spatial and mechanical reasoning, and in the auditory figure-background abilities.

Keywords: Multilingualism; Hearing Tests; Speech Perception; Intelligence Tests 


\section{INTRODUCTION}

As a result of all the advances and the process of globalization that have occurred in recent decades, the use of two or more languages the majority of the population has become a common practice. Therefore, there is a growing interest of experts in investigating the acquisition and processing of language and its cognitive and neural bases. They also wish to understand the implications of bilingualism on the cognitive development of bilingual individuals ${ }^{1}$. However, little research has been conducted on aspects of auditory performance.

Bilingualism is a frequent reality in the Rio Grande do Sul, due to the great occurrence of European immigration. According to the census published by the Brazilian Institute of Geography and Statistics (IBGE) in 1940, there were 747,859 inhabitants in Rio Grande do Sul (RS) who did not speak Portuguese in their homes, but German $(393,934)$ or Italian $(295,995)^{2}$ instead. Currently, in the region, locals still learn both the language of their ancestors and Brazilian Portuguese simultaneously ${ }^{3}$.

Pioneer researchers ${ }^{4,5}$ consider that bilingualism is a factor that fosters linguistic awareness and, as a consequence, language development. In this sense, they suggest that bilingual individuals have more cognitive flexibility than monolinguals.

Benefits were evidenced in bilingual subjects as regards maintenance of cognitive functions, which includes an increase of neural connections, increased vocabulary and greater functional reorganization of cerebral activity ${ }^{6}$. Previous studies have suggested that bilinguals may have better performance on measures that evaluate verbal skills ${ }^{7}$, and they may also have greater mental flexibility and a more diverse set of mental abilities ${ }^{8}$; moreover, cognitive characteristics, such as the executive functions of inhibitory control and attention, are much more evident ${ }^{9}$.

Thus, it is imperative, in the present study, to assess auditory abilities and cognitive symptoms in this population, because the ability to understand speech must be regarded as the most important of the measurable aspects of human auditory function. The latter is essential for normal communication, and it is dependent on auditory abilities ${ }^{10}$.

When using two languages, individuals face situations of conflicting information by means of two different linguistic concepts which pose a great challenge. Facing this challenge allows them to enhance the auditory abilities involved in this process; one of them is the auditory figure-background ability, especially for verbal sounds ${ }^{3}$.

Thus, the objective of this research is to evaluate the cognitive and auditory abilities of monolingual and bilingual individuals, as well as analyze and compare the results found in different measurements.

\section{METHODS}

This is an observational, cross-sectional, descriptive and quantitative study that compared the findings of the cognitive and auditory abilities of monolingual and bilingual adults. It was conducted in the Speech Pathology Clinic of the Federal University of Santa Maria, and approved by the Research Ethics Committee under certificate no. 0098.0.243.000-11, with acceptance of participants by signing an Informed Consent Form.

The sample was composed of normally hearing individuals, ranging in age between 18 and 25 years, with complete secondary education and socially active lifestyle. They were divided into two groups:

Control group (CG): composed of males and females, monolingual speakers of Brazilian Portuguese as their mother tongue.

Study group (SG): composed of males and females, bilingual speakers of Brazilian Portuguese as their mother tongue and German or Italian as a second language.

These were the eligibility criteria for both groups: age between 18 and 25 years; audiological diagnosis of auditory thresholds within normal standards, with threetone average at 500,1000 and $2000 \mathrm{~Hz} \leq 25 \mathrm{dbHL}$ (decibel hearing level); socially active lifestyle; complete secondary education; absence of evident neurological disorders; absence of earwax, tympanic perforation or otitis externa or hearing complaints. In addition, for the CG, the participants should be monolingual speakers of Brazilian Portuguese, but no fluency in speaking nor comprehension of any other language. For participation in the SG, the participants should be bilingual, native speakers of Brazilian Portuguese and speakers of German or Italian as a second language, with fluency in speaking and comprehension.

For composition of the sample, approximately 147 individuals were invited by telephone and e-mail. They were inhabitants of a region of Italian and German colonization, in towns and cities located near the city where the evaluations were carried out. An appointment was scheduled for 115 subjects; 95 of them were assessed in the first stage, in which it was found 
that 87 individuals met the eligibility criteria. For the second stage, only 21 individuals returned for cognitive assessments.

In this way, the CG was formed by eight subjects between the ages of 20 and 25 years, and the SG, by 13 subjects between the ages of 18 and 25 years. It should be emphasized that in this study, the following aspects were not taken into account: age of acquisition of a second language, cognitive processes underlying the acquisition pathways and their relations with the typological characteristics of languages acquired. By contrast, the study was focused on bilingualism in itself as a characteristic of the subject and the habitual use of language socially.

In the first stage, the participants were submitted to specific anamnesis. They answered a particular questionnaire about bilingualism in order to provide information about the acquisition of a second language, as well as the situations and the time of daily use of a second language for the purpose of checking their fluency. Then, the researchers carried out a visual inspection of the external acoustic meatus and a basic audiological evaluation to determine auditory thresholds at 500,1,000,2,000,4,000, 3000, 6000 and $8,000 \mathrm{~Hz}$ by air conduction, as well as the speech recognition threshold and the speech recognition percentage index.

Subsequently, the individuals who met the eligibility criteria, as checked in the above-mentioned evaluations, were evaluated by means of the Staggered Spondaic Word (SSW) Test, adapted to Brazilian Portuguese $^{11}$. It was applied by presenting the words recorded at an intensity of $50 \mathrm{~dB}$ SL (decibel Sensation Level), with three-tone average at 500, 1000 and 2000 $\mathrm{Hz}$. This test was chosen because it is considered as a low predictability instrument with greater linguistic load when compared to other dichotic tests, hence it provides a high level of difficulty.

In the second stage, an evaluation was made of cognitive abilities, by means of the Reasoning Test Battery (BPR-5) ${ }^{12}$, which was applied by an expert psychologist in the field, individually or in pairs. This battery is organized in two versions: Version $A$ is applied to elementary school students while Version B, to secondary education or higher education students. Thus, Version B was applied for the purpose of data collection.

BPR-5 is an instrument for assessment of cognitive abilities which provides estimates of the general cognitive functioning and of the strengths and weaknesses in five specific fields, namely: (a) Abstract Reasoning (AR), composed of 25 items, with a time limit of 12 minutes, associated with fluid intelligence. It indicates the ability to establish abstract relations in new situations for which there is little previously learned knowledge; b) Verbal Reasoning (VR), composed of 25 items, with a time limit of 10 minutes. It is associated with fluid intelligence and crystallized intelligence, and indicates the extent of vocabulary and ability to establish abstract relations between verbal concepts; c) Spatial Reasoning (SR), composed of 20 Items, with a time limit of 18 minutes. It assesses one's ability of visualization, i.e., mentally make visual representations of objects and manipulate them by transforming them into new representations. It is related to visual processing capacity, and it is also partially associated with fluid intelligence; d) Numerical reasoning (NR), composed of 20 items and time limit of 18 minutes. It corresponds to the assessment of fluid intelligence, as well as quantitative understanding. It indicates the capacity of reasoning with numeric symbols in quantitative problems and knowledge of basic arithmetic operations; e) Mechanical Reasoning (MR), composed of 25 items, with a time limit of 15 minutes. It assesses practical knowledge of mechanics and physics acquired in everyday experiences and practices. It is a test which assesses crystallized intelligence; however, because of the graphical representation of the items, it can also be considered to assess visual processing and fluid intelligence, since it requires some capacity to relate information ${ }^{12-14}$.

The application of the battery consisted of a brief introduction to explain the objectives of the study; then, the instructions were read aloud and the participants' questions were answered before the beginning of each sub-test. The tests were applied with limited time, as previously indicated. The order of presentation of the sub-tests was AR, VR, SR, NR and MR. They were applied in approximately 50 minutes.

To calculate the score of the reasoning tests, the gross scores, consisting of the sum of scores in each sub-test, were converted into Normalized Standard Scores (NSS). Also, the total scores achieved in all sub-tests of the battery were also converted into NSS. In addition to NSS scoring, the guidelines of the test also provides the values in percentiles, hence the individuals' correct answers could be compared.

The data were analyzed descriptively and received statistical treatment, using the SPSS software, version 9.0. The Mann Whitney U-test was used to compare the 
performance of the $C G$ and the $S G$, for the variables VR, AR, NR, MR, SR and SSW; statistical significance level of $p<0.05(5 \%)$. The results that showed statistical significance were marked by an asterisk (*).

\section{RESULTS}

Tables 1 and 2 show the descriptive measures and comparative tests of the CG and SG in the BPR-5 test.

Table 3 shows the descriptive measures and comparative tests of the CG and the SG in the SSW test.

Table 1. Distribution of groups of monolingual (CG) and bilingual (SG) normally hearing individuals, as regards overall performance in the BPR-5 test

\begin{tabular}{|c|c|c|c|c|c|c|}
\hline & \multicolumn{2}{|c|}{$\begin{array}{c}\text { CG - Monolinguals } \\
(n=08)\end{array}$} & \multicolumn{2}{|c|}{$\begin{array}{l}\text { SG Bilinguals } \\
(n=13)\end{array}$} & & \\
\hline & S1 & 34 & S9 & 74 & & \\
\hline & S2 & 76 & $S 10$ & 59 & & \\
\hline & S3 & 78 & $\mathrm{~S} 11$ & 83 & & \\
\hline & S4 & 53 & S12 & 78 & & \\
\hline & S5 & 49 & $\mathrm{~S} 13$ & 88 & & \\
\hline & S6 & 52 & S14 & 83 & & \\
\hline & S7 & 70 & $\mathrm{~S} 15$ & 62 & & \\
\hline & S8 & 57 & S16 & 81 & & \\
\hline & & & S17 & 65 & & \\
\hline & & & S18 & 75 & & \\
\hline & & & S19 & 80 & & \\
\hline & & & S20 & 88 & & \\
\hline & & & S21 & 75 & & \\
\hline \multirow{2}{*}{$\begin{array}{c}\text { Performance } \\
\text { Overall }\end{array}$} & Mean & SD & Mean & SD & p-value & d \\
\hline & 58.63 & 15.042 & 76.46 & 9.324 & $<0.01^{*}$ & -1.46 \\
\hline
\end{tabular}

Mann-Whitney U-test; $\left({ }^{*}\right)$ statistically significant value.

Caption: CG - Monolingual control group; SG - Bilingual study group; n- number of subjects; S- Subject; SD - Standard Deviation

There was a statistically significant difference between the monolingual and the bilingual subjects in the cognition tasks. The bilinguals had better overall cognitive performance.

Table 2. Distribution of groups of monolingual (CG) and bilingual (SG) normally hearing individuals, as regards performance in the cognitive abilities of the BPR-5 test

\begin{tabular}{ccccccc}
\hline & \multicolumn{2}{c}{ CG - Monolinguals } & \multicolumn{2}{c}{$\begin{array}{c}\text { SG Bilinguals } \\
(\mathbf{n}=\mathbf{1 3})\end{array}$} & Significance & Effect Size \\
\cline { 2 - 7 } & Mean & SD & Mean & SD & p-value & d \\
\hline Verbal R. & 16.00 & 2.878 & 19.54 & 2.602 & $<0.05^{\star}$ & -1.29 \\
Abstract R. & 14.75 & 4.921 & 18.15 & 2.193 & $>0.05$ & -0.95 \\
Numerical R. & 8.13 & 3.682 & 10.92 & 3.593 & $>0.05$ & -0.76 \\
Spatial R. & 9.38 & 4.207 & 13.38 & 3.305 & $<0.05^{\star}$ & -1.06 \\
Mechanical R. & 10.38 & 3.852 & 14.46 & 3.856 & $<0.05^{\star}$ & -1.05 \\
\hline
\end{tabular}

Mann-Whitney U-test; $\left({ }^{*}\right)$ statistically significant value.

Caption: CG - Monolingual control group; SG - bilingual study group; n- number of subjects; R- reasoning. 
A statistically significant difference was found between the monolingual and the bilingual subjects in cognition tasks, and it was indicative that the bilinguals performed better in verbal, mechanical and spatial reasoning skills.

Table 3. Distribution of groups of monolingual (CG) and bilingual $(S G)$ normally hearing individuals, as regards performance in the auditory figure-background ability for verbal sounds in the SSW test

\begin{tabular}{|c|c|c|c|c|c|c|c|c|c|}
\hline & \multicolumn{4}{|c|}{ Control group $(n=08)$} & \multicolumn{4}{|c|}{ Study group ( $n=13)$} & \multirow{2}{*}{ p-value } \\
\hline & Mean & SD & Min & $\operatorname{Max}$ & Mean & SD & Min & Max & \\
\hline SSW & 93.28 & 2.69 & 88.75 & 96.88 & 98.17 & 0.90 & 96.25 & 98.75 & $<0.01^{*}$ \\
\hline
\end{tabular}

Mann-Whitney U-test; $\left(^{*}\right)$ statistically significant value.

Caption: SD- Standard Deviation; Min- Minimum; Max- Maximum

There was a statistically significant difference between the monolingual and bilingual subjects in auditory tasks, showing that the bilinguals had better figure-background ability for verbal sounds.

\section{DISCUSSION}

The aim of this study was to discuss particular aspects of the cognitive and auditory abilities of bilingual individuals and contribute to the debate about the positive aspects in the bilingualism-cognitionhearing relationship.

The analyses of the measurements obtained in the BPR-5 battery showed a statistically significant difference in the overall performance of bilinguals, when compared with monolinguals. This clearly shows that bilinguals differ from monolinguals when they need to respond to activities that have a higher demand of cognitive functions (Table 1). These findings corroborate a study ${ }^{15}$ which found that bilinguals had a better score in 15 out of $18 \mathrm{IQ}$ tests used in the research, and a neutral effect in three of them.

Previous studies indicate that bilingualism accelerates the development of the relative general cognitive abilities, mainly attention and inhibition, and the facilitating effects of bilingualism are found in tasks in which these abilities are required ${ }^{16}$. Also, bilingual individuals have more cognitive reserves ${ }^{17}$ and outperform in tasks that place greater demand on their cognitive abilities ${ }^{18}$. Therefore, bilingual subjects have clear benefits when they maintain their cognitive ability, e.g., an increase of neural connections, increased vocabulary and greater functional reorganization of the cerebral activity, and greater metalinguistic awareness ${ }^{6}$.

Thus, it is believed that the results for the subjects of the present study corroborate findings previously cited in the literature, because the evaluated individuals had better overall cognitive scores, which evaluates various cognitive abilities, and requires greater demand on these abilities (Table 1).

As regards the specific aspects addressed in this study, the results of the analyses made in each of the measures of the BPR-5 battery showed a statistically significant difference in performance for VR, SR and MR of bilinguals, compared with monolinguals. For $A R$ and NR tests, there were no differences between the groups (Table 2).

In the reasoning tests that were positively influenced by bilingualism, it can be seen that they have some factors in common, e.g. the ability to reason and relate previously learned concepts, and they are influenced by sensory stimuli (Table 2). Thus, it can be stated that bilingualism may have a positive influence on some of the factors that compose the different types of intelligence, mainly those relative to fluid intelligence, attention, memory, auditory processing and processing speed.

These findings are in line with the theoretical assumptions underlying BPR-5 which adopt the terminology and definitions presented by Carrol, Horn and Woodcock (the $\mathrm{CHC}$ model) ${ }^{19}$, which have a multidimensional vision. In the $\mathrm{CHC}$ model, intelligence is composed of ten factors: fluid intelligence, crystallized intelligence, quantitative understanding, reading and writing, short-term memory, visual processing, auditory processing, storage capacity and recovery of long-term memory, processing speed and quick decision-making ${ }^{20,21}$.

In the literature, these aspects have been studied under different approaches. In a context of exposure to two different languages, there are two situations: in the first one, the presence of greater linguistic context increases the speed and effectiveness of information 
processing; in the second situation, there is conflicting information in two different linguistic concepts, causing a positive disruption of information processing ${ }^{22}$. The findings of the present study corroborate those of the above-mentioned authors, since the bilinguals showed better performance in verbal, mechanical and spatial reasoning tasks. This is particularly relevant for the verbal performance of these individuals (Tables 2 and 3).

A study conducted with bilingual speakers of English and Tamil has shown that the bilinguals showed better performance in tests focused on verbal and spatial intelligence, receptive vocabulary, attention and selection, in comparison with their monolingual peers ${ }^{23}$. The findings of the present study agree on those of the above-mentioned authors, i.e., there were also differences in tasks involving verbal and spatial intelligence. Reasoning of the verbal measures showed higher scores when compared with the others (Table 2), which corroborates the fact that bilinguals may outperform in verbal measures ${ }^{7}$.

Bilinguals may have greater mental flexibility, greater capacity to form concepts and a more diverse set of mental skills ${ }^{8}$. Cognitive characteristics, such as the executive functions of inhibitory control and attention, are much more evident in bilinguals ${ }^{9}$. These descriptions were found in the subjects of the present study (Tables 2 and 3).

With regard to aspects of auditory processing, it was found that bilinguals have better ability of speech understanding in competitive listening (Table 3). When auditory figura-background ability was assessed, measured through the SSW, there was a statistically significant difference between monolinguals and bilinguals. The latter showed better results (Table $3)$, which corroborates the findings of another study, also performed in the south of Brazil, which reported the advantage of bilingual individuals ${ }^{3}$. These findings also emphasize that inhibitory control and attention are much more evident in bilinguals ${ }^{9,24}$, which influences performance in the SSW.

The bilingual experience is an advantage in the improvement of the auditory system, which becomes efficient, flexible and focused on automatic sound processing, especially in complex conditions of listening, as can be seen in our findings (Table 2 and 3 ). These results agree on previous reports in the literature which have claimed that bilinguals have greater mental flexibility, working memory capacity and goal-directed attention ${ }^{7,25}$.
A previous study ${ }^{22}$ analyzed auditory behavior in tests for recognition of temporal patterns (Pitch and Duration Pattern Sequence Test) and dichotic listening of familiar (Dichotic Digits Test) and unfamiliar (Staggered Spondaic Words/SSW in Portuguese) two-syllable words. The subjects were Japanese descendants, speakers of Brazilian Portuguese and Japanese (GJJ); Portuguese-speaking Japanese descendants who do not speak Japanese (GJP) and non-descendants who speak Portuguese (GBP). The findings showed that the auditory experience provided by bilingualism facilitated performance in the SSW - the only test which showed a significant difference in favor of bilinguals (GJJ), between the evaluated groups. These results corroborate the findings of the present research (Table 3).

In international research, dichotic tests are applied to bilinguals to check whether or not there are differences in auditory information processing, while taking into account the activation of different brain hemispheres. The reason lies in the fact that previous studies have shown the relationship between learning a non-native language and anatomical and functional differences of the cerebral cortex in bilingual individuals ${ }^{26}$. These studies have also suggested that early bilinguals presented bilateral hemispheric involvement when using a language, while late monolinguals and bilinguals would have one dominant hemisphere ${ }^{27,28}$. However, the present study is focused on bilateral hemispheric activity, based on the total responses of the tests (Table 3).

The structure of the human brain is changed by the experience of acquiring a second language ${ }^{29}$. These researchers claim that bilinguals have a higher density of gray mass in the inferior parietal lobe in the left hemisphere and that structural reorganization in this region is related to proficiency and age of acquisition of a second language. This study has reported benefits of bilingualism in cognition and hearing tests, which in turn, may be related to the aspects mentioned above ${ }^{29}$.

Bilinguals have advantages when solving problems that involve conflicting information ${ }^{30}$ and effort to ignore such information. These advantages entail a better performance in various types of cognitive processing. According to a previous study ${ }^{14}$, the ability to inhibit attention given to conflicting information is a significant advantage of processing. This is aspect that corroborates the results of the present study, since abilities of attention and inhibition of conflicting information were 
significantly outperformed by bilinguals in the evaluated sample (Table 3).

These findings suggest that, because bilinguals have more controlled attention, such attention has a positive effect on the ability to decode and recognize messages. Compared with monolinguals, bilinguals have better performance as they focus their attention to the task with relevant information and keep their attention on this information, despite adverse interference ${ }^{25,31}$. That way, when considering that attention is an aspect that has great influence on performance in the SSW test, the findings of this research confirm previous reports in the literature.

The development of the auditory system can be fostered when an individual is exposed to two different languages. This occurs because exposure to two languages provides greater linguistic context, which increases the speed and effectiveness of information processing ${ }^{22}$.

Thus, based on the findings of several studies that have addressed bilingualism, cognition and hearing, it can be concluded that bilingualism is an experience that has significant consequences for good cognitive performance and hearing of individuals ${ }^{32}$. In the present study, this fact can be clearly seen, because the bilinguals showed better performance in cognitive and auditory tasks that they had performed (Tables 1, 2 and 3).

\section{CONCLUSION}

Based on this study, it was found that bilingualism has had a positive influence on the development of cognitive and auditory abilities, which resulted in better performance by bilinguals, compared with monolinguals, in verbal, spatial and mechanical reasoning abilities, as well as in auditory figure-background ability for verbal sounds.

\section{REFERENCES}

1. Kroll JF, Dussias PE, Bice K, Perrotti L. Bilingualism, mind, and brain. Annu Rev Linguist. 2015;1(1):377-94.

2. Spinassé KP. O hunsrückisch no Brasil: a língua como fator histórico da relação entre Brasil e Alemanha. Espaço Plural. 2009;19(1):117-26.

3. Gresele ADP, Garcia MV, Torres EMO, Santos SN, Costa MJ. Bilinguismo e habilidades de processamento auditivo: desempenho de adultos em tarefas dicóticas. CoDAS. 2013;25(6):506-12.
4. Bain B. Bilingualism and cognition: Towards a general theory. In: ST Carey (ed). Bilingualism, biculturalism and education: University of Alberta Press, Edmonton. 1974. p. 119-28.

5. Cummins J. The influence of bilingualism on cognitive growth: a synthesis of research findings and explanatory hypotheses. Working Papers on Bilingualism. 1976;9(1):1-43.

6. Bialystok E. Cognitive effects of bilingualism: how linguistic experience leads to cognitive change. Int. J. Bilingual Education Bilingualism. 2007;10(3):210-24.

7. Filippi R, Leech R, Thomas M, Green D, Dick F. A bilingual advantage in controlling language interference during sentence comprehension. Bilingualism: Language and Cognition. 2012;15(11):858-72.

8. Edwards J. Foundations of bilingualism. In: Bhatia TK, Ritchie WC (eds). The handbook of bilingualism. Malden, MA: Blackwell Publishing. 2004. p.7-31.

9. Bialystok E, Craik FIM, Luk G. Bilingualism: consequences for mind and brain. Trends Cogn Sci. 2012;16(4):240-50.

10. Jacob LCB, Alvarenga KF, Zeigelboim BS. Avaliação audiológica do sistema nervoso auditivo central. Arq. Int. de Otorrinolaringol. 2000;4(4):144-51.

11. Borges ACLC. Adaptação do teste SSW para a língua portuguesa: nota preliminar. Acta Awho. 1986;5(1):38-40.

12. Almeida LS, Primi R. Baterias de Provas de Raciocínio - BPR-5. São Paulo: Casa do Psicólogo;1998.

13. Primi R, Almeida LS. Estudo de validação da Bateria de Provas de Raciocínio (BPR-5). Psic.: Teor. e Pesq. 2000;16(2):165-73.

14. Cruz MBZ. Estudo de validade e precisão da bateria de provas de raciocínio infantil - BPR-5. [Dissertação] Itatiba (SP): Universidade de São Francisco; 2008.

15. Baker C, PrysJones S. Encyclopedia of bilingualism and bilingual education - school or education. Clevedon: Multilingual Matters; 1998.

16. Bialystok E, Shapero D. Ambiguous benefits: the effect of bilingualism on reversing ambiguous figures. Developmental Science. 2005;8(6):595-604.

17. Vian Jr O, Wessheimer J, Marcelino M. Bilinguismo: aquisição, cognição e complexidade. Revista do GELNE. 2013;15(1):399-416.

18. Nobre APMC, Hodges LVSD. A relação bilinguismo-cognição no processo de 
alfabetização e Letramento. Rev. Ciências \& Cognição. 2010;15(3):180-91.

19. Primi R, Almeida LS. Perfis de Capacidades Cognitivas na Bateria de Provas de Raciocínio (BPR-5). Psicol. Esc. Educ. 2004;8(2):144-65.

20. Primi R. Inteligência: Avanços nos modelos teóricos e nos instrumentos de medida. Aval. Psicol. 2003;2(1):67-77.

21. Wechsler SM, Schelini PW. Bateria de habilidades cognitivas Woodcock-Johnson III: validade de construto. Psic.: Teor. e Pesq. 2006;22(3):287-96.

22. Onoda RM, Pereira LD, Guilherme A. Reconhecimento de padrão temporal e escuta dicótica em descendentes de japoneses, falantes e não-falantes da língua japonesa. Rev Bras Otorrinolaringol. 2006;72(6):737-46.

23. Bialystok E, Martin MM. Attention and Inhibition in bilingual children: Evidence from the dimensional change card sort task. Dev. Science. 2004;7(3):325-39.

24. Astheimer LB, Berkes M, Bialystok E. Differential allocation of attention during speech perception in monolingual and bilingual listeners. Lang Cogn Neurosci. 2016;31(2):196-205.

25. Yang $H$, Yang S, Ceci SJ, Wang GQ. Effects of bilinguals' controlled-attention on working memory and recognition. Proceedings of the 4th International Symposium on Bilingualism edited by: Cohen J, Mcalister KT, Rolstad K, Macswan J. Cascadilla Press Somerville, MA, 2005.

26. Sanchez ML, Nunes FB, Barros F, Ganança $\mathrm{MM}$, Coavilla HH. Avaliação do processamento auditivo em idosos que relatam ouvir. Rev Bras Otorrinolaringol. 2008;74(6):896-902.

27. Hull R, Vaid J. Laterality and language experience. Laterality: asymmetries of body, brain and cognition. 2006;11(5):436-64 .

28. Hull R, Vaid J. Bilingual language lateralization: a meta-analytic tale of two hemispheres. Neuropsychologia. 2007;45(9):1987-2008.

29. Mechelli A, Crinion JT, Noppeney U, O'doherty J, Ashburner J, Franckowiak RS et al. Structural plasticity in the bilingual brain. Nature. 2004;431 (710):757.

30. Morales J, Gómez-Ariza CJ, Bajo MT. Dual mechanisms of cognitive control in bilinguals and monolinguals. Journal of Cognitive Psychology. 2013;25(5):531-46.
31. Zimmer M, Finger I, Scherer L. Do bilinguismo ao multilinguismo: intersecções entre a psicolinguística e a neurolinguística. ReVEL. 2008;6(1):1-28.

32. Bialystok E. Bilingualism: The good, the bad, and the indifferent. Bilingualism: Lang. and Cogn. 2009;12(1):3-11. 